\title{
Securitizing Area Insurance: A Risk Management Approach
}

\author{
Pasquale Lucio Scandizzo \\ University of Rome "Tor Vergata”, Rome, Italy \\ Email: scandizzo@uniroma2.it
}

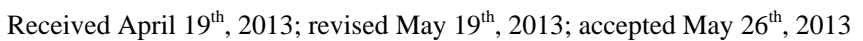

\begin{abstract}
Copyright (C) 2013 Pasquale Lucio Scandizzo. This is an open access article distributed under the Creative Commons Attribution License, which permits unrestricted use, distribution, and reproduction in any medium, provided the original work is properly cited.
\end{abstract}

\begin{abstract}
This paper examines the possibility of developing a risk management instrument by designing a financial security whose value is linked to the average revenue of a given area. This type of program is sufficiently general to be considered for any group of businesses that face production uncertainty. In agriculture, it has been proposed as an alternative to multiple peril crop insurance programs, as area yield, revenue or rainfall insurance in order to eliminate ex ante and ex post moral hazard. While most of the literature concentrates on the determination of value of the indemnity and the payment of such an insurance, this paper focuses on the fact that, unlike other forms of insurance, area insurance can be cast in the form of a hedging security and, as a consequence, rather than depending only on the demand for diversification (the beta of the Capital Asset Price Model), it makes possible a risk shifting strategy based on the heterogeneity of risk attitudes of the economic agents operating in a given area.
\end{abstract}

Keywords: Risk; Insurance; Moral Hazard; Security

\section{Introduction}

Objective of this paper is to present and analyze the characteristics of a new type of contingent contract, aimed at securitizing insurance against production risks. While the concept proposed has a wider applicability, this paper considers in particular the case of area insurance. This is an insurance program that pays an indemnity proportional to an indicator of average revenue or income for a given area. In the case of agricultural AI, for example, the indicator may be directly yield, or some other statistic, such as rainfall, that can be used as a reliable predictor for the revenue shortfall, which is the object of insurance. The greatest advantage of AI and GI is that, unlike other insurance programs, and provided that the subject insured is not large enough to affect the average revenue of the area, this type of program is almost completely free of moral hazard. In the USA, experience with area insurance in agriculture began in 1990, when the farm bill provided funds for the Federal Crop Insurance Corporation (FCIC) to pilot-test new insurance products. The Group Risk plan was the first of these experimental programs, introduced in 1993 as a pilot area-yield crop insurance for soybeans. This program was followed in 1994, as a consequence of budgetary provisions in the 1993 Omnibus Budget Reconciliation Act, by a mandate to FCIC to offer area based insurance on about 1200 counties for barley, cotton, peanuts, grain sorghum, soybeans, and wheat. Although these contracts have not appeared to be very popular with farmers so far, commitment of FCIC has remained strong over the years, and the coverage of the program has been considerably extended (more than 30,000 ) from the limited number of farmers (less than $12,000)$ participating in the first two years.

A recent application of GI insurance is Group Risk Income Protection (GRIP), an area-based revenue insurance product that pays the insured in the event the county average per-acre revenue falls below the insured's "trigger revenue.” GRIP derives from the Group Risk Plan of Multiple Peril Crop Insurance. The addition of a price component to GRP to form a revenue guarantee was developed by Dr. Bruce Babcock and Dr. Dermot Hayes, Professors of Economics, Iowa State University. GRIP is linked to the Chicago Board of Trade (CBOT) negotiations, since its expected price is defined as the simple average of the last five final daily settlement prices in February on the CBOT December corn futures contract and the nearby November soybean futures contract for the current crop year. Harvest price, on the other hand, is defined as the simple average of the final closing daily settlement prices in November on the CBOT nearby December corn futures contract and in October on the nearby CBOT November soybean futures contract for the current crop year. A GRIP indemnity payment will occur if the county revenue is less than the producer's trigger revenue based on the selected coverage level.

In this paper, I examine the possibility of designing a risk management instrument through a financial security whose value is linked to the average revenue of a given area. This type of program is sufficiently general to be considered for any group of businesses that face production uncertainty. In agriculture, it has been proposed as an alternative to multiple peril crop insurance programs, as area yield, revenue or rainfall insurance (Miranda, 1991, 1999; Skees et al., 1997) in order to eliminate ex ante and ex post moral hazard. Within the same context, Mahul (1999) and Mahul et al. (2010) have shown how to determine the optimum value of the indemnity and the payment of such an insurance. However, I focus on the fact that, unlike other forms of insurance, area insurance (AI) can be cast in the form of a hedging security and, as a consequence, rather than depending only on the demand for diversification (the beta of the Capital Asset Price Model), it makes possible a risk shifting 
strategy based on the heterogeneity of risk attitudes of the economic agents operating in a given area.

\section{The Competitive Market Model}

Assume that a group of farmers of a given area are engaged in the production of several crops, i.e. corn, wheat, soybeans, etc., and that the income resulting from production is uncertain, because it depends on weather, pest attacks, price fluctuations and other random events. The i-th farmer chooses the number of acres allocated to each crop by maximizing the expected value of utility, which is defined as function increasing in the farmer's net revenue (positive first derivative). The utility function is also supposed to be such that its increase declines with income increases (negative second derivative). Formally, indicating with $U_{i}$ the utility index for the i-th farmer, with $y_{i}=\left\{y_{i j}\right\}$ the vector of total income generated by the $\mathrm{j}$-th crop, with $x_{i}$ the vector $\left\{x_{i j}\right\}$ of the number of acres allocated to the j-th crop, and with $\rho_{i}$ the vector $\left\{\rho_{i j}\right\}$ of the stochastic net revenue per ha of the j-th crop, we can formulate the decision problem of the $\mathrm{i}$-th farmer as follows:

$\max E U_{i}\left(y_{i}\right)$; subject to:

$$
y_{i}=\rho_{i}^{\prime} x_{i}, D x_{i} \leq b_{i}
$$

where $E$ is the expectation operator, primes denote transposes, $D=\left\{d_{k j}\right\}$ is a matrix of input-output coefficients, measuring the quantity of the $k$-th factor required to produce one unit of the $\mathrm{j}$-th crop, and $b_{i}=\left\{b_{i k}\right\}$ is a vector of resource constraints for the i-th farm $(k=1,2, \cdots, K)$. Taking a second order Taylor series approximation of the utility function around the mean values of the random variables $\left\{\rho_{i j}\right\}$, or, alternatively, assuming that the $p_{i j}$ 's are distributed according to a two parameter distribution (e.g. the normal), we obtain the familiar E-V utility function:

$$
U_{i}=U_{i y} p_{i}^{\prime} x_{i}+0.5 U_{i y y}\left(x_{i}^{\prime} \Omega_{i} x_{i}\right),
$$

where $p_{i}=E \rho_{i}, U_{i y}=\left\{\mathrm{d} U_{i} / \mathrm{d} y_{i}\right\}$ denotes the first derivative (i.e. the marginal utility) of each farmer with respect to total income from all crops,

$$
U_{i y y}=\left\{\mathrm{d}^{2} U_{i} / \mathrm{d} y_{i}^{2}\right\}<0
$$

is the corresponding second derivative, and $\Omega_{i}=\left\{\sigma_{i j m}\right\}$ is the variance-covariance matrix of crop incomes per ha of the i-th farm $p_{i j}$.

Dividing both sides of (2) by $U_{i}$, we can re-write the problem in (1) as follows:

$$
\max E V_{i}=p_{i}^{\prime} x_{i}-0,5 \phi_{i}\left(x_{i}^{\prime} \Omega_{i} x_{i}\right), \text { subject to: } D x_{i} \leq b_{i} .
$$

where $V_{i}=U_{i} / U_{i y}$ and $\phi_{i}=-\left(U_{i y y} / U_{i y}\right)$ equals Pratt coefficient of absolute risk aversion.

To solve this problem, form the Lagrangean:

$$
L=p_{i}^{\prime} x_{i}-0.5 \phi_{i}\left(x_{i}^{\prime} \Omega_{i} x_{i}\right)-\lambda_{i}^{\prime}\left(D x_{i}-b_{i}\right)
$$

where $\lambda_{i}=\left\{\lambda_{i k}\right\}$ is a vector of Lagrange multipliers.

The Kuhn-Tucker conditions for the solution of (3) can be written as follows:

$$
p_{i m}-\phi_{i} \sum_{j=1}^{J} \sigma_{i j m} x_{i j}-\sum_{k=1}^{K} d_{i k m} \lambda_{i k}=0 \text { or } x_{i m}=0, m=1,2, \cdots, J
$$

$$
\sum_{j=1}^{J} d_{i k j} x_{i j}-b_{i k}=0 \text { or } \lambda_{i k}=0, k=1,2, \cdots, K
$$

Expression (5) states the well known condition of optimality requiring that for each crop to which a non zero area is allocated, expected revenue per ha be equal to the risk premium plus the cost per ha of all inputs evaluated at the shadow prices $\lambda_{i k}$. Each of these shadow prices, according to condition (6), on the other hand, are non zero only if the corresponding resource constraint is binding.

Let's introduce now the possibility of acquiring (going long or short) a security, which yields to long holders a random payoff

$$
I=g(S-\xi),
$$

where $g$ is a positive constant, for $S>\xi$, and requires a given payment $I=-C$ for $S \leq \xi$ for long holders. For short holder, the situation would be reversed, as they would receive a payoff $C$ from the long holders for $S \leq \xi$ and would pay them $I=g(S-\xi)$ for $S>\xi$. S is thus the trigger level for the payoff,

$$
\xi=\frac{1}{\sum_{i=1}^{n} \sum_{j=1}^{J} x_{i j}} \sum_{i=1}^{n} \sum_{j=1}^{J} x_{i j} \rho_{i j}
$$

is random revenue per ha in the area (i.e. for all farmers considered). Denoting with $G(\xi)$ the distribution function of area revenue per ha, the expected value of the premium is

$$
E I=\int_{0}^{R} g(R-\xi) \mathrm{d} G(\xi)-c(1-G(R)) .
$$

We can reformulate the i-th farmer maximization problem as follows:

$$
\begin{aligned}
& \max _{x_{i}, q_{i}} E V_{i}=\max \left[p_{i}^{\prime} x_{i}+q_{i} E I-0.5 \phi_{i}\right. \\
& \left.\times\left(x_{i}^{\prime} \Omega_{i} x_{i}+q_{i}^{2} \sigma_{I}^{2}+2 q_{i} x_{i}^{\prime} \operatorname{Cov}\left(\rho_{i}, I\right)\right)\right]
\end{aligned}
$$

subject to: $D x_{i}-b_{i} \leq 0 ; \quad x_{i j} \geq 0 \quad i=1,2, \cdots, n ; j=1,2, \cdots, J$

The objective function for the i-th farm in (7) is now formed of four parts: 1) the expected value of net farm revenue from crop production, 2) the expected gain from holding (long or short) the security, 3) the risk premium for crop production, 4) the risk premium for holding the security, 5) the conjoint risk premium to hold a portfolio with both crops and the security. Note that the i-th farmer decides the number of hectares $x_{i j}$ to allocate to the $\mathrm{j}$-th crop $(j=1,2, \cdots, J)$ and the number of (ha equivalents) $q_{i}$ of securities to hold. Note also that $q_{i}>0$ in the case of "long" holding (or buying) and $q_{i}<0$ in the case of short holding (or selling).

The formulation in (7) describes the planning problem of a risk averse farmer (assuming $\phi_{i}>0$ ). This agent is offered the opportunity to go long (i.e. to buy) or short (to sell) on an insurance-like security based on the average revenue accruing from a set of activities (e.g. agriculture) within a given area or otherwise defined group of agents. In practice, rather than average income, which is difficult to observe directly, the security, in exchange for a premium $c$ paid by the "long" agent (respectively, paid to the "short" agent) in the years where an observable variable $z$ (for example, rainfall or any other index that can be easily observed and is correlated with area revenue) is above a trigger level $R$, pays the amount $h(R-z)$ in the "bad years". Denoting with $F(z)$ the distribution function for $z$, assum- 
ing $z$ is non-negative, we can compute the expected value of $I$ as follows:

$$
E I=\int_{0}^{R} h(R-z) \mathrm{d} F(z)-c(1-F(R))
$$

The Kuhn-Tucker conditions for the solution of problem (7) may be written by adding to the constraint in (7) the following:

$$
\begin{gathered}
p_{i}-\phi_{i}\left(\Omega_{i} x_{i}+q_{i} \operatorname{Cov}\left(\rho_{i} I\right)\right)-D_{i}^{\prime} \lambda_{i} \leq 0 \\
E I-\phi_{i}\left(\sigma_{I}^{2} q_{i}+x_{i}^{\prime} \operatorname{Cov}\left(\rho_{i}, I\right)\right)=0,
\end{gathered}
$$

where $\lambda_{i}$ is a vector of shadow prices. Expression (9) states that for all non zero activities expected revenues per ha should equal marginal costs, where these are given by risk premiums, inclusive of insurance, and by resource opportunity costs evaluated at shadow prices. Expression (10), on its part, states that the insurance net payoff should itself equal its risk premium.

Indicating with the sign * the vectors and the submatrices corresponding to non zero activities, and applying the variance and covariance definitions, we can write:

$$
\begin{aligned}
p_{i}^{*} & =\phi_{i}\left(\Omega_{i}^{*} x_{i}^{*}+q_{i} \beta_{i}^{*} \operatorname{Cov}(z, I)\right)+D^{* \prime} \lambda_{i}^{*} q_{i} \\
& =\left(E I-\phi_{i}\left(x_{i}^{\prime} \beta_{i} \operatorname{Cov}(z, I)\right) / \phi_{i} \sigma_{I}^{2}\right)
\end{aligned}
$$

where $p_{i}^{*}$ is a $J^{*}, 1$ vector of revenues per ha for non zero farm activity levels $x_{i j}^{*}, j=1,2, \cdots, J *, \operatorname{Cov}(z ; I)$ is the covariance between $I$ and $z$, and $\beta_{i}$ is the vector of coefficients obtained by projecting linearly the differences between the i-th farm revenue per ha and the corresponding mean onto the difference between the statistical indicator $z$ of total revenue per ha of the area involved in the scheme and the corresponding mean according to the so called "regressability assumption” (Benninga et al., 1984):

$$
\rho_{i}-p_{i}=\beta_{i}(z-E z)+u_{i}
$$

$u_{i}$ being a (vector valued) random variable independent of $y$. According to this assumption, for each crop, the difference between farm revenue per ha and its mean can be decomposed linearly into two parts: one proportional to the difference between the current value and the mean value of an indicator of revenue per ha of the entire area involved in the scheme, and an independent, idiosyncratic random component, representing non diversifiable risk. Each component of the vector $\beta_{i}$ is a coefficient $\beta_{i j}$ similar to the widely known coefficient of the Capital Asset Pricing Model (CAPM) and measures the sensitivity of the revenue per ha of the j-th crop to movements in area revenues per ha.

Going back to the maximizing conditions, expression (11) states that prices of all non zero activities should equal marginal costs at the optimum, while expression (12) indicates that the quantity of insurance acquired by the i-th firm equals the net value of the insurance, including its utility from risk diversification. This result can be seen more clearly, dropping the asterisks for simplicity, by writing it as follows:

$$
q_{i}=\frac{\int_{0}^{R} h(R-z) F(z) \mathrm{d} z-c(1-F(R))}{\phi_{i} \sigma_{z}^{2} F(R)}+x_{i}^{\prime} \beta_{i}
$$

where

$$
\frac{\operatorname{Cov}(z, I)}{\sigma_{I}^{2}}=-1,
$$

But

$$
\operatorname{Cov}(z, I)=-\sigma_{I}^{2}=-\sigma_{z}^{2} F(R)^{1},
$$

so that the correlation between area revenue and the insurance is

$$
\frac{\operatorname{Cov}(z, I)}{\sigma_{z} \sigma_{I}}=-\sqrt{F(R)} .
$$

This brings us to state the following proposition:

Proposition 1. The amount of the security purchased (sold) by each farmer is proportional to the ratio between her expected gain and her risk premium (the subjective "benefit-cost ratio") plus the agent's relative gain from diversification (her objective benefit-cost ratio).

Dividing (14)) by

$$
\sum_{J} x_{i j}=x_{i}^{\prime} \iota
$$

where $l$ is the $J^{*}, 1$ sum vector, we obtain the expression for the amount of coverage, defined as the ratio of the quantity purchased or sold of the security in ha equivalents to total cultivated has of the individual farm:

$$
\frac{q_{i}}{x_{i}^{\prime} l}=\frac{\int_{0}^{R} h(R-z) \mathrm{d} F(z)-c(1-F(R))}{\eta_{i} \sigma_{z}^{2} F(R)}+\beta_{i x}
$$

where $\eta_{i}$ denotes the relative coefficient of risk aversion of the i-th agent and

$$
\beta_{i x}=\frac{x_{i}^{\prime} \beta_{i}}{x_{i}^{\prime} \iota}
$$

is the ratio between the beta of the individual crop and the land cultivated for the i-th agent.

Corollary 1. The amount of coverage purchased (sold) will be proportional to the sum of two terms: 1) the individual ratio between the expected net benefit and the risk premium, and 2) the weighted average of the agent betas.

Comment. The insurance program introduces an element of risk due to the variability of area revenue. Those who go long on the security, in fact, pay in every period a premium $c$ to those who go short on the same security, unless area revenue (or its proxy) is below its threshold level, in which case the "shorters" will have to pay the "longers" a compensation.

The compensation paid by the "shorters" to the "longers", in turn, will be a function of the difference between current area revenue (or the current value of the proxy used) and the threshold. Demand for the security will be larger, the higher the trigger value for the payment of the indemnity, the smaller the risk premium that each farmer is willing to pay to hold the security, the lower the premium to be paid to the short holders and the higher the correlation between the performance of the buyer and the average performance in the area. On the other hand, supply for the security will be larger, the larger the premium

$$
\begin{aligned}
\operatorname{Cov}(z, I)= & \int_{z} \int_{c<R} y(R-z) \mathrm{d} F(z, I)-c(1-F(R)) \\
& -E y R F(R)+(E y)^{2}+c(1-F(R)) E z \\
= & -\left(E z^{2}-(E z)^{2}\right) F(R)=-\operatorname{Var}(z)
\end{aligned}
$$


paid to shorters, the lower the risk premium and the larger, in absolute value, the negative correlation between the supplier's revenue per ha and area revenue per ha. Note also that in order to hold the security, it is not necessary that the agent is a producer, i.e. the diversification component may be zero and the quantity of the security purchased (sold) may still be positive. In this case, the agent holding (long or short) the security will act as a pure speculator.

Equation (15) can be interpreted as the demand for holding long the security (for $q_{i}>0$ ) and the demand for holding it short $\left(q_{i}<0\right)$.Since each unit of the security promises to yield a net expected revenue of

$$
E I=F(R) E_{r} h(R-z)-c(1-F(R))
$$

to long holders and $-E I$ to short holders, the demand elasticity with respect to the payment to be made is

$$
-\frac{c(1-F(R))}{E I-x_{i}^{\prime} \beta_{i} \phi_{i} \sigma_{z}^{2} F(R)}
$$

for long holding and

$$
-\frac{F(R) E_{r} h(R-z)}{E I-x_{i}^{\prime} \beta_{i} \phi_{i} \sigma_{z}^{2} F(R)}
$$

for short holding.

In equilibrium, demand for insurance should equal supply so that the sum of excess demand

$$
\sum_{i}^{n} q_{i}=0
$$

Summing over all farms the terms in (15) and solving for $c$, we can thus find the equilibrium value of the premium for the insurance policy:

$$
c=\frac{F(R)}{1-F(R)}\left[E_{R} h(R-z)+\Phi\left(\frac{X}{n \beta_{z}}\right) \sigma_{z}^{2}\right]
$$

where.

$$
\Phi=n\left(\sum_{i=1}^{n} \phi_{i}^{-1}\right)^{-1}
$$

is the harmonic mean of the individual risk aversion coefficients, $\mathrm{H}=\Phi(X / n)$ is the corresponding average relative risk aversion coefficient, evaluated at the average level of cultivated land in the area,

$$
E_{R} h(R-z)=E(h(R-z)-t)
$$

for $\mathrm{z} \leq R$, and I have used the property:,

$$
\sum_{i=1}^{n} x_{i}^{\prime} \beta_{i} \beta_{z}=X, \quad X=\sum_{i=1}^{I} \sum_{j=1}^{J} x_{i j}
$$

is total land cultivated in the area and $\beta_{z}=\operatorname{Cov}(z, \xi) / \sigma_{z}^{2}$ is the linear regression coefficient of the indicator $z$ with respect to average area revenue per ha ${ }^{2}$.

Proposition 2. The payment for the short holders of the security is equivalent to an insurance premium. The level of the premium that equilibrates demand and supply is always greater

\footnotetext{
${ }^{2}$ Using again the regressability assumption, we can write:

$z=E z+\beta_{z}(\xi-E \xi)+v$,

where $V$ is a randomly distributed disturbance. Substituting into (13), we obtain: $\rho_{i}=p_{i}+\beta_{i} \beta_{i}(\xi-E \xi)+\beta_{i} v+u_{i}$
}

than the actuarially fair premium (i.e. the expected value of the payoff for the long holders) depending on the average (area) risk premium from holding the security.

Comment. Given the number of traders, in equilibrium the expected value of the payoff for both long and short holders equals the average premium for risk that the farmers involved in the scheme are willing to pay. Therefore, the premium to be paid (respectively, to pay) from those who buy (to those who sell) the security will equal the sum of the expected indemnity and of the average (in the harmonic mean sense) subjective risk. The premium will be greater than its "actuarially fair" level of a loading factor reflecting average risk aversion (in the harmonic mean sense), where the average is taken over both long and short security holders. An increase in the risk aversion of any agent, in other words, increases the premium (i.e. the "take" of the short holders) independently on whether this concerns somebody who would buy or sell the security.

Corollary. The equilibrium expected level of the equivalent premium (the payment to short holders) equals the expected utility gain of the average (in the harmonic mean sense) agent.

Comment. Expression (17) shows that, in order to be feasibly supported by the farmers of a given area, the contract proposed must be "fair" in the sense that the expected charge should equal the expected utility gain of a representative farmer. Such an agent is defined as one, whose absolute (or relative computed at the mean) risk aversion coefficient is the harmonic mean of the risk aversion coefficients of all other farmers supporting the scheme. In other words, in order for the scheme to be sustainable, the representative agent should be unable to gain (or lose) on average from purchasing or selling the security. This notion of fairness does not coincide with the usual actuarial notion, since a risk loading factor is added to the actuarially fair premium.

Substituting (16) into (15), we obtain:

$$
q_{i}=\left(x_{i}^{\prime} \beta_{i}-\frac{X}{n \beta_{z}} \frac{\Phi}{\phi_{i}}\right)
$$

Using the definition of relative risk aversion, we can also write:

$$
\frac{q_{i}}{x_{i}^{\prime} l}=\left(\beta_{i x}-\frac{H}{\eta_{i} \beta_{z}}\right)
$$

where $\mathrm{H}$ and $\eta_{i}$ are both coefficients of relative risk aversion respectively at the overall average and average revenue level for the i-th agent.

Proposition 3. The equilibrium holding level for the i-th farmer of an area insurance security is independent of both the size of the premium and the trigger level for the indemnity. It equals the difference between a measure of the demand for diversification (the average beta of the farmer) and the reciprocal of a measure of relative risk aversion (the ratio of average to the farmer's own risk aversion coefficient).

Comment. In equilibrium, the expected value of the payoff equals the average risk premium of the participants to the scheme (Proposition 2). Thus, while the expected payoff for long and short holders will vary with the trigger level of the indemnity, the equilibrium level of the amount of the security bought and sold by each farmer will not. Proposition 3 translates into the simple rule: whatever the indemnity expected, buy (sell) the security for a share equal to your average beta minus the ratio of average to your risk aversion coefficient. The rea- 
son for this is that the demand for the security depends in the first instance on the degree to which it will diversify the portfolio of the productive activities of the farmer. Because carrying the security implies an additional risk, this degree, which can be measured by the weighted beta, has to be corrected with the ratio between average and individual risk aversion. The larger this ratio, the larger the risk that the farmer is willing to carry with respect to the average, thus requiring less insurance. Demand (and supply) for the security will be zero if all farms are identical (all betas are equal to one) and all risk aversion coefficients are also equal. In general, however, the amount of the security demanded (offered) will be larger (smaller) the larger (the smaller) the correlations involved (between the index and area revenue and between own and area revenue), and the smaller (the larger) the ratio between average and own risk aversion. For example, if the i-th agent risk aversion is twice the harmonic mean, and $\beta_{i}=1$, optimum coverage will be $1 / 2$. Note, in particular, that even if all farmers' revenues are positively correlated with area revenues, it will pay for some of them to go short on the security. A sufficient heterogeneity in risk aversion, in other words, will ensure that a market for the hedging security may develop even in the absence of negative correlations across farms. For the same reason, in equilibrium, we may expect pure speculators to hold short positions.

From Equation (5), by totally differentiating with respect to $q_{i}$, we can derive for the $\mathrm{m}$-th crop:

$$
\frac{\mathrm{d} x_{i}}{\mathrm{~d} q_{i}}=\left[\phi_{i} \Omega_{i}+D^{\prime} \frac{\partial \lambda_{i}}{\partial x_{i}}\right]^{-1}\left[\phi_{i} \beta_{i} \sigma_{z}^{2} F(R)\right] \text { for all } x_{i m}>0
$$

Provided that matrix in the square parenthesis is full, it will also be positively definite since the first term is the variancecovariance matrix, while the second is the matrix given by the product of the input-output coefficients by the shadow prices. This matrix will be singular if the number of factors is smaller than the number of products, but its sum with a full variance covariance matrix will also be full. Moreover, by the properties of shadow prices at the optimum, an increase in crop production may not result in a decrease in any shadow price

$$
\text { (i.e. } \frac{\partial \lambda_{i k}}{\partial x_{i j}} \geq 0 \text { for all } i, k, j \text { ). }
$$

Thus, we can state the following proposition:

Proposition 4. In equilibrium, for long holders of the security, production of the crops whose revenues per ha are positively (negatively) correlated with area revenue per ha increases (decreases). For short holders, production of the crops whose revenues per ha are negatively (positively) correlated with area revenue increases (decreases).

Comment. The introduction of area insurance determines a differentiation in farm portfolio holdings, since farms now hold, in addition to their cultivated plots, a security whose performance is negatively correlated with average performance over all farms and crops. If the m-th crop revenue per ha is positively correlated with area revenue, two effects will ensue: 1) a reduction of production costs, due to the possibility of expanding its production and covering its risk by going long on the security, and 2) an increase in costs due to the fact that insurance incurporates a risk premium depending on average risk aversion and on the variance of area revenue. For long holders, the first effect will dominate the second one, while the opposite will occur for short holders. By a basic property of mathematical program- ming, since the introduction of a new dimension of optimization is equivalent to the removal of a constraint, we have that $D^{\prime} \lambda(q) \leq D^{\prime} \lambda(\bar{q})$, i.e. the shadow cost of the resources decreases as a consequence of the introduction of the security. This implies a higher first term on the right hand side of Equation (19). For $q_{i}>0$, and $\beta_{i m} \geq 0$ (i.e. the $\mathrm{m}$-th crop is positively correlated with area revenue, production of the $\mathrm{m}$-th crop will thus unequivocally increase, since shadow costs are lower and the risk premium to hold the new security is also lower. In other words, farmers can now hedge the crops that are positively correlated with area revenue by going long on a security which is also negatively correlated with area revenue. If $q_{i}<0$, and $\beta_{i m} \leq 0$, we have a similar result. In other words, farmers who grow crops that are negatively correlated with area revenue can now hedge them by going short on a security which is also negatively correlated with area revenue. For the same reasons, we will see a reduction of the production of long holders (short holders) crops negatively (positively) correlated with area revenue. These crops, in fact, do not offer any further opportunity to increase earnings because of the introduction of the new security.

\section{Conclusion}

In this paper I have shown that area insurance may be molded in the form of a security or a contingent claim, whose payoff depends on the value taken by a statistic of a given population. This statistic, which may be the value of average or median income, revenue or yields, or any statistic correlated with it (e.g. rainfall), displays a value that changes with the state of nature. When the statistic is below a critical level, the people who have gone "short" on the security will pay a premium, while when it is above the critical level, they will collect a payment from those who have gone "long". Actuarial group or area insurance may be considered a special case where only one insurer goes short on the equivalent security, by committing herself to pay the premium in the "bad" states, in exchange for the payment in the good states.

The rewards that the security promises to long and short holders possess some simple properties. First, the amount of the security purchased (sold) by each agent is proportional to the ratio between her expected indemnity and her risk premium (the subjective "benefit-cost ratio") plus the agent's relative gain from diversification (his objective benefit-cost ratio). Second, given an expected reward for long holders, the security pay off for short holders that equilibrates demand and supply is greater than the actuarially fair premium and depends positively on the average (area) risk premium from buying or selling insurance. Third, the equilibrium expected level of the premium charged for the security equals the expected utility gain of the average (in the harmonic mean sense) agent. Fourth, the optimal level of insurance demanded or supplied in equilibrium will be proportional to the ratio of the beta of each agent to her share of total activity level minus the ratio of average relative risk aversion to the agent's own risk aversion coefficient.

\section{REFERENCES}

Benninga, S., Eldor, R., \& Zilcha, I. (1984). The optimal hedge ratio in unbiased futures markets. Journal of Futures Markets, 4, 155-159.

Feder, G., Just, R. E., \& Schmitz, A. (1980). Futures markets and the theory of the firm under price uncertainty. Quarterly Journal of Eco- 


\section{P. L. SCANDIZZO}

nomics, 317-328.

Mahul, O. (1999). Optimum area yield crop insurance. The American Journal of Agricultural Economics, 81, 75-83.

Mahul, O., \& Stutley, C. (2010). Government support to agricultural insurance: Challenges and options for developing countries. World Bank Publications.

Miranda, M. L. (1991). Area yield crop insurance reconsidered. American Journal of Agricultural Economics, 73, 233-242.
Skees, J. R., Black, J. R., \& Barnett, B. J. (1997). Designing and rating an area yield crop insurance contract. American Journal of Agricultural Economics, 79, 430-438.

Vargas Hill, R., Kumar, N., \& Hoddinott, J. (2010). Adoption of weather-index insurance: Learning from willingness to pay among a panel of households in rural Ethiopia. Mimeo: IFPRI. 